\title{
PATHOEPIDEMIOLOGY OF CERVICAL CANCER IN NATIONAL INSTITUTE OF CANCER RESEARCH AND HOSPITAL OF BANGLADESH
}

\author{
JABEEN $\mathrm{S}^{1}$, ISLAM MJ ${ }^{2}$, TALUKDER MH ${ }^{3}$, NURUNNABI ASM ${ }^{4}$, HAQUE $^{5}$
}

\begin{abstract}
:
A study was conducted to find out the descriptive epidemiological and pathological characteristics among the incidental cases of cervical cancer patients attending National Institute of Cancer Research \& Hospital (NICRH), Dhaka, Bangladesh, during January to December, 2012. In this hospital based case-control study 278 patients with histologically, cytopathologically or by the oncologists confirmed cervical cancer were compared with equal number of controls, who had cancers other then cervical, form the same hospital. The mean ages for the cervical cancer cases were 44.90 7.217 years. The morphological categorization of the cervical cancer patients was squamous cell carcinoma (93\%) and rest adenocarcinoma (7\%). The majority of cases presented with moderately differentiated or grade 2 lesions (45.9\%). There were no in-situ cases. Almost all the cancers cases (90.9\%) had regional lymph node involvement. Odds ratios (OR) and 95\% confidence intervals (CI) were obtained from multivariate logistic regression analysis. Compared with controls, it was found that cases having higher education (OR=1.46, 95\% CI: 1.35-6.42), more personal income $(O R=0.129,95 \% \mathrm{CI}$ : .02-.24), small family size $(\mathrm{OR}=0.018,95 \% \mathrm{CI}$ : 27.88-120.95) had a decreased risk for cervical cancer. However, marital status (OR=1.97, 95\% CI: 4.21-20.69), age at marriage (OR=2.57, 95\% CI: 11.45-118.29), age at $1^{\text {st }}$ child $(O R=9.33$, 95\% CI: 0.14-0.65), had more risk for cervical cancer. This study concludes that the majority of the cervical cancer sufferers at NICRH were from lower-socioeconomic group having less education with a late cancer presentation mostly with squamous cell carcinoma.
\end{abstract}

Key words: Cervical cancer, pathoepidemiology, risk factors.

J Dhaka Med Coll. 2014; 23(2) : 203-210.

\section{Introduction:}

Cervical cancer is one of the most common cancers among women worldwide; ${ }^{1}$ in the developing countries, cervical carcinoma ranks second, whereas in the developed countries, it ranks fifth. ${ }^{2}$ It is estimated that about 132,082 women die due to cervical cancer every year, accounting for $26.7 \%$ of the worldwide incidence. ${ }^{1}$ Cervical cancer ICD-10 category $\mathrm{C} 53^{3}$ is one of the common neoplastic diseases affecting women. In developing countries, cervical cancer was the most frequent neoplastic disease among women until the early 1990s, when breast cancer became the predominant cancer. ${ }^{1}$ Cancer cervix still occupies either the top rank or second among cancers in women in many developing countries.

According to Cancer Registry Report, cervical cancer is the second most common cancers among Bangladeshi females (21.5\%). ${ }^{4}$ Globocan grades the world region into 5 categories, on a rising scale of 1 to 5 on the basis of the age standardized incidence rates of the country or the estimates of the same prepared by IRC. ${ }^{5}$ In the first category (grade I) are included countries with a cervical cancer incidence

1. Dr. Suraiya Jabeen, Assistant Professor, Department of Community Medicine, Dhaka Medical College, Dhaka.

2. Dr. Md. Johirul Islam, Assistant Professor, Department of Cancer Epidemiology, National Institute of Cancer Research and Hospital, (NICRH), Dhaka.

3. Dr. Md. Habibullah Talukder, Associate Professor \& Head, Department of Cancer Epidemiology, National Institute of Cancer Research and Hospital, (NICRH), Dhaka.

4. Dr. Abu Sadat Mohammad Nurunnabi, Assistant Professor, Department of Anatomy, OSD, Directorate General of Health Services (DGHS), Dhaka.

5. Prof. Musarrat Haque, Professor \& Head, Department of Community Medicine, Shaheed Suhrawardy Medical College, Dhaka.

Correspondence: Dr. Suraiya Jabeen, Assistant Professor, Department of Community Medicine, Dhaka Medical College, Dhaka. Cell Phone: +8801730-002094, Email: jabeens2009@gmail.com 
(ASR) below 9.4 per 100,000. The other categories are grade 2 (ASR $<16.8$ per 100,000 ), grade 3 (ASR $<25.8$ per 100,000$)$, grade 4 (ASR<33.4 per 100,000) and grade 5 (ASR<87.3 per 100,000). Though we have no population based cancer registry, we are unable to category our status. But from hospital based cancer registry statistics we can assume that it is the number two cancers among the women in our country. ${ }^{6}$

In Canada, cervical cancer was frequent, but now ranks 11 th for incidence and 16th for cancer-related mortality. Approximately 1,300 women were diagnosed and about 350 women died from the disease in Canada during $2011 .{ }^{7}$ Canada was an early adopter of cervical cancer screening from 1949 in British Columbia with gradual intensification across the country. The understanding that nearly all cervical cancer is caused by oncogenic strains of the human papillomavirus (HPV) has assisted in better interpretation of the associations between behavior and cervical cancer. ${ }^{8}$

Epidemiological studies conducted during the past 30 years have consistently indicated that cervical cancer risk is strongly influenced by measures of sexual activity, number of sexual partners, age at first sexual intercourse and sexual behavior of the women's male partners. ${ }^{9}$ Many studies have also suggested that women with multiple sexual partners are at high risk for HPV acquisition and cervical cancer. ${ }^{10}$

The number of live births is a consistent risk factor for cervical cancer. There is a linear trend in the association between parity and risk. ${ }^{9}$ There is an excess risk of cervical cancer associated with long-term use (e"12 years) of oral contraceptives. The association is somewhat stronger for adenocarcinoma than for squamous cell carcinomas. ${ }^{9}$ The evidence for an effect of diet on risk of cervical cancer indicates that a high intake of foods containing beta carotene and vitamin $\mathrm{C}$ and, to a lesser extent, vitamin A may reduce the risk of cervical cancer. ${ }^{9}$ The WHO's International Agency for Research on Cancer (IARC) classified HPV infection as "carcinogenic" to humans (HPV types 16 and 18), "probably" carcinogenic (HPV types 31 and 33) and "possibly" carcinogenic (other HPV types except 6 and 11). ${ }^{11}$ It is now well established that HPV infection is the central causal factor in cervical cancer. ${ }^{12}$

In a recent study, more than $99 \%$ of cases of cervical cancer worldwide were estimated to contain HPV DNA. The virus infects the cells of the cervix and slowly causes precancerous cellular changes (dysplasia) that can progress. These cellular changes can be relatively mild and often do not progress or may regress. ${ }^{13}$ Larger deeper lesions are more likely to progress to cancer. Women generally are infected with HPV in their teens, 20s, or 30s; it can take as long as 20 years after HPV infection for the cancer to develop. Cervical cancer starts with an in situ stage that can be treated, but it then progresses to invasive disease that is always fatal in countries where appropriate surgery and radiotherapy are unavailable. ${ }^{14}$

Primary prevention of cervical cancer through preventing human papillomavirus (HPV) infection, a sexually transmitted agent that causes cervical cancer, will contribute to reducing cancer mortality. Secondary prevention involves using relatively cheap screening and treatment technologies that can detect dysplasia before it progresses to invasive cancer. ${ }^{15}$

A lack of effective screening programme aimed at detecting and treating precancerous conditions is the key reason for the much higher cervical cancer incidence in developing countries. It has been estimated that only about $5 \%$ of women in developing countries have been screened for cervical dysplasia in the past 5 years, compared with $40 \%$ to $50 \%$ of women in developed countries. ${ }^{16}$

The present study was done with the objective of examining descriptive epidemiological and pathological characteristics of cervical cancer at National Institute of Cancer Research \& Hospital (NICRH), Dhaka, Bangladesh.

\section{Methods:}

This case-control study was conducted at National Institute of Cancer Research \& Hospital (NICRH), Dhaka, Bangladesh. Cases (cervical cancer patients) \& matched controls (other than cervical cancer) were both collected from NICRH. This study was done on females 
aged e"35 years. Cases indicate all incident (within 6 months of diagnosis) cases of cervical cancer, confirmed histopathologically, cytopathologically or by the oncologists. All the cervical cancer cases from outdoor and indoor during data collection period were collected. Matched controls were collected from the same hospital. This study was conducted from January to December, 2012.

The required sample size of this case-control study was calculated by estimating an odds ratio with specified relative precision. ${ }^{17}$ In this study, purposive sampling technique was followed. All the cases and controls fulfilling the above mentioned selection criteria were included, till the target of 278 cases and 278 controls. An interview schedule with semistructured questionnaire was used for data collection. No sensitive or privacy invasive questions were asked. Female interviewers were taken for data collection. After explaining the purpose of the study, and obtaining consent from the eligible cases and controls, data collection was carried out through face to face interview by asking questions in Bangla. After fulfilling all inclusion and exclusion criteria first a case was interviewed from NICRH and then the matched control. Controls were matched by religion, residential status and age ( \pm 2 years).

All the data were checked and edited after collection. Then data was entered into computer, with the help of software, SPSS for Windows version 15.0). First chi-square analysis was done. Later these variables that are related with cervical cancer were examined to figure out which variables increase or reduce the risk factor for cervical cancer by calculating $\mathrm{OR}$ and logistic regression analysis.

The present study was approved by the research and evaluation authority of the National Institute of Cancer Research \& Hospital (NICRH), Dhaka, Bangladesh.

\section{Results:}

This study was conducted among the 556 respondents attending NICRH, Dhaka, during study period. Cases and controls were equal in numbers. The mean age of cases were $44.90 \pm 7.217$ years, and same for controls were $45.40 \pm 8.227$ years. About $41 \%$ of the respondents were from 41-50 years age group,
$33 \%$ from 40 years or below and $20 \%$ were above 51 years age. Majority (90\%) of the respondents were married in both the groups. Rests $10 \%$ were either widowed or divorced. Almost all $(82 \%)$ were Muslims. About $46 \%$ of the respondents were illiterate, $27 \%$ were primary educated and 19\% had secondary education. Almost all (95.7\%) the respondents were home maker, rest $4.3 \%$ were from different working groups. About $91 \%$ respondents had no personal income, among them majority were from cervical cancer group. Chi-square test shows significant association $\left(x^{2}=9.225, \mathrm{df}=1 ; \mathrm{p}=0.002\right)$ between cervical cancer and personal income (table I).

\section{Table I}

Sociodemographic parameters of the respondents $(N=556)$

\begin{tabular}{|c|c|c|c|}
\hline \multirow[t]{2}{*}{ Variables } & \multicolumn{2}{|c|}{ Respondents } & \multirow[t]{2}{*}{ Total (\%) } \\
\hline & Cases & Controls & \\
\hline \multicolumn{4}{|l|}{ Age group (years) } \\
\hline$\leq 40 \mathrm{yrs}$ & 103 & 112 & $215(33.1)$ \\
\hline $41-50$ yrs & 126 & 103 & $229(41.2)$ \\
\hline $51-60$ yrs & 42 & 50 & $92(16.5)$ \\
\hline$\geq 61 \mathrm{yrs}$ & 07 & 13 & $20(3.6)$ \\
\hline \multirow{2}{*}{\multicolumn{4}{|c|}{$\begin{array}{l}\mathrm{x}^{-} \text {age for cases } 44.90(\mathrm{SD} \pm 7.217) \mathrm{yrs} \text {; for controls } \\
\mathrm{x}^{-} 45.40(\mathrm{SD} \pm 8.227) \mathrm{yrs}\end{array}$}} \\
\hline & & & \\
\hline \multicolumn{4}{|l|}{ Residential status } \\
\hline Urban & 36 & 36 & $72(13.0)$ \\
\hline Rural & 242 & 242 & $484(87.0)$ \\
\hline \multicolumn{4}{|l|}{ Religion } \\
\hline Muslim & 228 & 228 & 456 (82.0) \\
\hline Hindu & 31 & 30 & $61(11.0)$ \\
\hline Christian & 14 & 14 & $28(05.0)$ \\
\hline Bhudist & 05 & 06 & $11(02.0)$ \\
\hline \multicolumn{4}{|l|}{ Education } \\
\hline Illiterate & 139 & 116 & $255(45.9)$ \\
\hline Primary & 71 & 81 & $152(27.3)$ \\
\hline Secondary & 46 & 57 & 103 (18.5) \\
\hline Higher secondary & 13 & 15 & $28(5.1)$ \\
\hline Graduate $^{+}$ & 9 & 9 & $18(3.2)$ \\
\hline \multicolumn{4}{|l|}{ Marital status } \\
\hline Married & 258 & 243 & 501 (90.0) \\
\hline Widow & 18 & 26 & $44(08.0 .0)$ \\
\hline Divorced & 02 & 09 & $11(02.0)$ \\
\hline \multicolumn{4}{|l|}{ Personal income } \\
\hline Yes & 17 & 33 & $50(09.0)$ \\
\hline No & 412 & 94 & 506 (91.0) \\
\hline \multicolumn{4}{|c|}{$x^{2}=9.225 ; d f=1 ; p=.002$} \\
\hline
\end{tabular}


About $47 \%$ of the respondents had menarche at 12 years age in cases. Mean age for cases was $12.44 \pm 0.928$ years. About $51 \%$ of the controls had menarche at 13 year, and their mean age was $13.03 \pm 0.893$ years. About $65 \%$ of the respondents were in multipara group. Among the cases majority (57.2\%) were multipara. Only $7 \%$ of the respondents were nullipara, among them majority were from control group. Highly significant association was found between parity and cervical cancer $\left(X^{2}=31.36 ; d f=3 ; p<0.001\right)$. The mean age at which the first child was born was $17.58 \pm 4.680$ years and that for control was 20.29 \pm 5.172 years. Association between cervical cancer and age of first child was born was highly significant $(\mathrm{p}<0.001)$. Among the respondents, $31.3 \%$ had history of taking OCP. Majority were from cervical cancer group. Chi-square test showed highly significant association $\left(\mathrm{X}^{2}=20.91\right.$; $\mathrm{df}=1$; $\mathrm{p}<0.001$ ) (table II).

\section{Table II}

Cases and controls by their reproductive history and OCP use

\begin{tabular}{|c|c|c|c|c|}
\hline & Cases (\%) & Controls (\%) & $\mathrm{X}^{2}$ & $\bar{P}$ \\
\hline \multicolumn{5}{|c|}{ Age at menarche } \\
\hline d"12 & 165 (59.3) & $63(22.7)$ & 15.765 & 0.001 \\
\hline $13-14$ & $110(39.6)$ & 204 (73.3) & & \\
\hline e"15 & $03(1.1)$ & $11(4.0)$ & & \\
\hline \multicolumn{5}{|l|}{ Parity } \\
\hline$\leq 2$ & $27(9.7)$ & $34(12.2)$ & 31.365 & $<.001$ \\
\hline$\geq 3$ & 251 (90.3) & $244(87.8)$ & & \\
\hline \multicolumn{5}{|c|}{ Age at first Issue } \\
\hline$\leq 20$ & 197 (70.9) & $112(40.3)$ & 29.575 & $<.001$ \\
\hline $21-29$ & $79(28.4)$ & $149(53.6)$ & & \\
\hline$\geq 30$ & $02(0.7)$ & $17(6.1)$ & & \\
\hline \multicolumn{5}{|c|}{ Oral contraceptive use } \\
\hline Ever & $91(32.7)$ & $43(15.6)$ & 20.912 & $<.001$ \\
\hline Never & $187(67.3)$ & $235(84.4)$ & & \\
\hline
\end{tabular}

Family members of the respondents in group, shows that, majority (58\%) were from 4-5 member groups and 28\% from 6-10 member groups, association was significant (tvalue $=78.121 ; \mathrm{p}=.018$ ) The families of the respondent were grouped into two groups to examine the relationship of cervical cancer and family size Odds ratio showed that the small family size group suffered less than the family size of three or more than five. The association was significant $(p=0.018 ; O R=0.96)$. The distribution of the respondents by age at marriage shows that the mean age of cases was $15.85 \pm 2.001$ ) years and that for control was $16.29 \pm 2.610$ years. Association between cervical cancer and age of marriage was significant $(p=0.027)$. Only $9 \%$ respondents gave positive history of tobacco smoking. Majority were from control group. Ninety one percent of the respondents did not smoke tobacco. Chi-square test was done, a significant association was found between cervical cancer and tobacco smoking $\left(X^{2}=5.62 ; d f=1 ; p=0.018\right)$. Out of 556 respondents, only $2.5 \%$ respondents had positive family history of cervical cancer. Significant association was found between cervical cancer and family member $\left(\mathrm{X}^{2}=10.073\right.$; $\mathrm{df}=1 ; \mathrm{p}=0.018)$. The mean soap use was 5.27 times for cervical cancer patients. Controls used soap (6.57) more times. A highly significant relationship of cervical cancer and soap use was found $(t=177.8 ; \mathrm{df}=554 ; \mathrm{p}=0.001$ ) (table III).

\section{Table III}

Outline of some test statistics and cervical cancer

\begin{tabular}{lcc}
\hline Variable & Test statistics & P-value \\
\hline Cervical cancer and & $\mathrm{t}$-value $=$ & .018 \\
family size & 78.121 & \\
Cervical cancer and age & $\mathrm{t}$-value $=$ & .027 \\
$\begin{array}{l}11.688 \\
\text { at marriage }\end{array}$ & $\mathrm{X}^{2}=5.62$ & .018 \\
$\begin{array}{l}\text { Cervical cancer and } \\
\text { tobacco smoking }\end{array}$ & \\
$\begin{array}{l}\text { Cervical cancer and family } \\
\text { history of cervical cancer }\end{array}$ & $\mathrm{X}^{2}=10.073$ & .018 \\
$\begin{array}{l}\text { Cervical cancer and soap } \\
\text { using habit }\end{array}$ & $\mathrm{t}$-value $=$ & $<.001$ \\
\hline
\end{tabular}

It shows that only $13 \%$ had positive history of UTI/HPV infection. Among them majority were from cervical cancer group. Insignificant association was found $\left(\mathrm{X}^{2}=2.729\right.$; $\mathrm{df}=1$; $\mathrm{p}=0.099)$. About $10 \%$ respondents did screening for cervical cancer, among them 
majorities were from control group. Among the 58 respondents who had screening for cervical cancer, 62\% did Pap test and rest had VIA. Lymph node involved of the respondents, showed that $91 \%$ had $\mathrm{LN}$ involvement and majority of them were cases. Cervical cancer cases by treatment received showed that almost $81 \%$ had surgery done, $15 \%$ had chemotherapy and only $4 \%$ had radiotherapy as treatment modality.

Multivariate logistic regression analysis was done on educational status, marital status, personal income, age at marriage, age at $1^{\text {st }}$ child and respondents' family size. It was found that cases having higher education $(\mathrm{OR}=1.46$, 95\% CI: 1.35-6.42), more personal income
(OR=0.129, 95\% CI: .02-.24), small family size $(\mathrm{OR}=.018,95 \% \mathrm{CI}: 27.88-120.95)$ had a decreased risk for cervical cancer. However, marital status (OR=1.97, 95\% CI: 4.21-20.69), age at marriage $(\mathrm{OR}=2.57,95 \% \mathrm{CI}: 11.45-$ $118.29)$, age at $1^{\text {st }}$ child (OR=9.33, 95\% CI: $0.14-$ 0.65), had more risk for cervical cancer development (table IV).

By primary histopathology of the disease showed that $66 \%$ had squamous cell carcinoma, $25 \%$ had duct cell carcinoma and all were from control group, $5.8 \%$ had adenocarcinoma majority were from cervical cancer group. Rest $3.5 \%$ had small cell and non small cell carcinoma, all belonged to control group | (table V).

Table IV

Logistic regression model with odds ratio and 95\% CI

\begin{tabular}{lcccc}
\hline Variables & Wald & P value & OR & 95\% CI \\
\hline Educational status & 19.910 & .001 & 1.46 & $1.35-6.42$ \\
Personal income & 9.179 & .002 & .129 & $.02-.24$ \\
Marital status & 14.587 & .001 & 1.97 & $4.21-20.69$ \\
Age at marriage & 60.936 & .027 & 2.57 & $11.45-118.29$ \\
Family member & 17.387 & .018 & 0.96 & $27.88-120.95$ \\
Age at $1^{\text {st }}$ child & 7.653 & $<.001$ & 9.33 & $0.14-0.65$ \\
\hline
\end{tabular}

$\mathrm{CI}=$ Confidence interval;

$\mathrm{OR}=$ Odds ratio

Table V

Distribution of the respondents by histopathological categories

\begin{tabular}{lccc}
\hline Primary histopathology & \multicolumn{2}{c}{ Respondents (\%) } & Total (\%) \\
\cline { 2 - 3 } of the disease & Case & Control & \\
\hline Squamous cell carcinoma & $259(93.2)$ & $108(38.8)$ & $367(66.0)$ \\
Adenocarcinoma & $19(6.8)$ & $13(4.7)$ & $32(5.8)$ \\
Duct cell carcinoma & 0 & $137(49.3)$ & $137(24.6)$ \\
Small cell carcinoma & 0 & $8(2.9)$ & $8(1.4)$ \\
Non small cell carcinoma & 0 & $3(1.1)$ & $3(0.5)$ \\
Others & 0 & $9(3.2)$ & $9(1.6)$ \\
\hline Total & $278(100.0)$ & $278(100.0)$ & $556(100.0)$ \\
\hline
\end{tabular}




\section{Discussion:}

The percentage of cervical cancer in NICRH, Dhaka, Bangladesh, is $19.2 \%,{ }^{6}$ which reflects that a good number of females are affected by cervical cancer. The demographic profile of the cervical cancer patients in NICRH was middle aged women with little or no education, a lower socioeconomic status, predominantly home makers. The malignancy was predominantly a moderately differentiated squamous cell carcinoma (SCC), with late presentation. There was a lower component of adenocarcinoma then otherwise reported in literature. ${ }^{18,19}$

In the present study, $87 \%$ of the patients were from the rural areas, suggesting, thereby, that cervical cancer largely affects the females from rural areas. Similar observations have been made earlier. ${ }^{20}$ In rural areas, women's health problems are often linked to nutritional deficiencies, excessive workload and frequent pregnancies coupled with inadequate prenatal and birth care. The primary reason given for this is lack of access to screening and health services and lack of awareness of the risk factors of cervical cancer. HPV infection and precancerous lesions go unnoticed and develop into full blown cancer before women realize that they need to go for medical help.

The mean ages of cases were 44.90 \pm 7.217 years; two thirds of the cervical cancer was observed in the women below 50 years of age. In the United States, more than half (58\%), while in India, in Mumbai city $45 \%$ and in Chennai city $43 \%$ of the cases were seen in women below 50 years. In India, the peak age for cervical cancer incidence is $45-54$ years. ${ }^{5}$

Carcinoma of the cervix is reported to be more common in females in the age group of 51-60 years. ${ }^{21}$ The findings of the present study are similar to that. Although cancer of the cervix can develop in women of all ages, it usually develops in women aged 35-55 years, with the peak age for incidence varying with different populations. ${ }^{22}$

Almost all the respondents were currently married in both the groups. Most of them had no personal income, and more than half of them belonged to 4-5 member family.
About two thirds of the cases were not educated, and almost all were house makers. About half of the cases had menarche at 12 years age.

The frequency of this malignancy has been found to be higher in the females who got married between 18 to 20 years of age. Our findings are consistent with the earlier reports. ${ }^{23}$ Early age at marriage indicates an early exposure to sexual activities and early pregnancy, which are well-known etiological factors for cancer cervix. These factors result in a longer duration of married life, with greater opportunities for sexual activities and increased chances of becoming pregnant. Carcinoma of the uterine cervix is predominantly a disease of married women, especially occurring in those who marry at an early age and have a long, active sexual life. ${ }^{23}$

About $13 \%$ of the respondents could report about having infection in past. The amount would be more, if they were more educated and aware about it. More than half of the cervical cancer patients were multipara and about one third had history of taking Oral contraceptive pills (OCP). Oral contraceptive use is associated with the development of cervical cancer. A systematic review of hormonal contraceptive use reported that the risk of in situ cervical cancer increased even for women with less than 5 years' hormonal contraceptive use; however, the risk of invasive cervical cancer increased only after 5 years' use. The risk for both conditions declined with time since last use of hormonal contraceptives, and there was no elevated risk for invasive cervical cancer 10 years since the end of exposure. ${ }^{21} \mathrm{~A}$ small group of respondents admitted about tobacco smoking. This would also be more important issue; however, smoking by women is not a popular culture in our society. However, it was found that more than half of the respondent's spouse or other family member was smokers.

Only $2.5 \%$ respondents had positive family history of different cancers. This result may not be the true picture as major portion of our population do not seek or reach modern health care facilities. Distribution of respondents by type of relation suffered from cancer showed that more than three fourths had first degree 
relation (mother and sisters). About 10\% respondents had screening for cervical cancer, among them majorities were from control group. Among them $62 \%$ did Pap's test and rest had screening on visual inspection by acetic acid (VIA).

Distribution of the respondents by gynaecological examination shows that only $13 \%$ underwent such examinations. 91\% respondents had lymph node involvement and majorities were from cases.

In different population based case-control studies, e.g. Jacqueline et al. ${ }^{15}$ and Bhurgri et al. ${ }^{19}$ found literacy as a factor associated with cervical cancer, which is similar to the findings of our study. Similarly, in our study, it was found that higher education $(O R=1.46)$, more personal income $(O R=0.129)$, small family size $(\mathrm{OR}=.018)$ had a decreased risk for cervical cancer. However, marital status ( $\mathrm{OR}=1.97)$, age at marriage $(\mathrm{OR}=2.57)$, age at $1^{\text {st }}$ child (OR=9.33), had more risk for development of cervical cancer.

The morphological categorization is important for management of cancer cervix. In our study, squamouscell carcinoma (93.2\%) and adenocarcinoma $(6.8 \%)$ were more evident. Western populations have recently documented a morphological shift with a rising adenocarcinoma component of cancer cervix; adenocarcinomas and adenosquamous carcinomas at present account for about 10\% of all cervical cancers. ${ }^{7}$

Parkin ${ }^{5}$ in 2002 drew an appropriate profile of the cancer cervix patient, reporting that the majority of the women belong to the lower socioeconomic status, are rural, aged between 3564 years and highly non compliant to treatment. This holds true for our NICRH, Dhaka, Bangladesh, cases. Unskilled workers and less well educated women were more frequently affected as they remain susceptible to other high risk factors viz. worse socioeconomic and marital conditions. These findings were also observed by other researchers in the region. ${ }^{24}$ The predominant risk factor in our study was early marriage, multiparity, long married life, poor socioeconomic condition, history of infection, less literacy, etc.

The results from the current study must be considered in light of certain limitations. Firstly, the study was carried out in a small group of 278 subjects for a period of one year only. Secondly, there is a possibility of re-call bias about some data, such as, age at menerche, age at marriage, age at $1^{\text {st }}$ issue, etc.

\section{Conclusion:}

The fraction of cervical cancer cases in NICRH, Dhaka, Bangladesh, indicates that there is a significant amount of high risk population with a late presentation. It can be suggested here that cervical screening if implemented should focus on once a life time methodology involving 36-45 year old women. This should be combined with HPV vaccination for the young, and public health education for all. This may burden the already stretched health resources of a developing country. Probable risk factors like early marriage, multiparity socioeconomic status, etc. associated with the development of cervical carcinoma detected in the present study could be minimized easily with minimum resources.

\section{References:}

1. Globocan cancer fact sheet. Available from: http:/ /globocan.iarc.fr/factsheets/cancers/cervix.asp. [accessed on November 11, 2011].

2. Bhattacharya N, Singh RK, Mondal S, Roy A, Mondal R, Roychowdhury S, et al. Analysis of molecular alterations in chromosome 8 associated with the development of uterine cervical carcinoma of Indian patients. Gynecol Oncol 2004; 95(2): 352-62.

3. ICD- 10 International Statistical Classification of Diseases and Related Health Problems.Tenth Revision. Vol 1. World Health Organization. Geneva. p.205.

4. Cancer Registry Report National Institute of Cancer Research \& Hospital, 2005-2007. December, 2009. MOHFW, GOB, NICRH \& WHO.

5. Parkin DM, Whelan SL, Ferlay J, Thomas DB. Cancer Incidence in Five Continents, Vol. VIII; IARC Scientific Publications No. 155. Lyon, France. 2002.

6. Hospital Cancer Registry Report. National Institute of Cancer Research \& Hospital, 2011-2013. (Short Draft). MOHFW, GOB, NICRH \& WHO. 
7. Franco EL, Duarte-Franco E, Ferenczy A. Cervical cancer: Epidemiology, prevention and the role of human papillomavirus infection. CMAJ 2001; 164(7): 1017.

8. Dickinson JA, Stankiewicz A, Popadiuk C, Pogany L, Onysko J, Miller AB. Reduced cervical cancer incidence and mortality in Canada: national data from 1932 to 2006. BMC Public Health 2012; 12: 992.

9. Schiffman MH, Brinton LA. Devesa SS, Fraumeni JF Jr. Cervical cancer. In: Schottenfeld D, Fraumeni JF Jr, eds. Cancer epidemiology and prevention. New York: Oxford University Press; 1996. p.1090-116.

10. Remschmidt C, Kaufmann AM, Hagemann I, Vartazarova E, Wichmann O, Delere Y. Risk factors for cervical human papillomavirus infection and high-grade intraepithelial lesion in women aged 20 to 31 years in Germany. Int $\mathrm{J}$ Gynecol Cancer 2013, 23(3): 519-26.

11. IARC Working Group on the Evaluation of Carcinogenic Risks to Humans. Human papillomaviruses. Vol 64 of IARC Monographs on the Evaluation of Carcinogenic Risks to Humans. Lyon: International Agency for Research on Cancer, World Health Organization; 1995.

12. Munoz N, Bosch FX, Desanjose S, Tafur L, Izarzugaza I, Gili M, et al. The causal link between human papillomavirus and invasive cervical cancer: a population-based case-control study in Colombia and Spain. Int $J$ Cancer 1992; 52: 743-9.

13. Walboomers JM, Jacobs MV, Manos MM, Bosch FX, Kummer JA, Shah KV, et al. Human papillomavirus is a necessary cause of invasive cervical cancer worldwide. J Pathol 1999; 189(1): 12-9.

14. Holowaty P, Miller AB, Rohan T, To T. Natural history of dysplasia of the uterine cervix. J Natl Cancer Inst 1999; 91(3): 252-8.
15. Jacqueline S, Cristina H, Christopher E. Cervical cancer in developing world. West J Med 2001; 175(4): 231-3.

16. World Health Organization. Control of cancer of the cervix uteri: review article based on a report of a WHO meeting, November 1985, Geneva. Bull World Health Organ 1986; 64: 607-18.

17. Lwonga SK, Lemeshow, Sample size determination in health studies: a practical manual. WHO Geneva, 1991. p.6-7.

18. Bhurgri Y, Bhurgri A, Pervez S, Bhurgri M, Kayani $\mathrm{N}$, Ahmed R, et al. Cancer profile of Hyderabad, Pakistan 1998-2002. Asian Pac J Cancer Prev 2006; 6(4): 474-80.

19. Bhurgri Y, Nazir K, Shaheen Y, Usman A, Faridi $\mathrm{N}$, Bhurgri $\mathrm{H}$, et al. Patho-epidemiology of cancer cervix in Karachi South. Asian Pac J Cancer Prev 2007; 8(3): 357-62.

20. Kaku M, Mathew A, Rajan B. Impact of socioeconomic factors in delayed reporting and latestage presentation among patients with cervix cancer in a major cancer hospital in South India. Asian Pac J Cancer Prev 2008; 9(4): 589-94.

21. Misra JS, Srivastava S, Singh U, Srivastava AN. Risk-factors and strategies for control of carcinoma cervix in India: hospital based cytological screening experience of 35 years. Indian J Cancer 2009; 46(2): 155-9.

22. Zeller JL, Lynm C, Glass RM. Carcinoma of the Cervix JAMA Patient page. JAMA 2007; 298(19): 2336.

23. Fotra R, Gupta S, Gupta S. Study of the cytogenetic and non-cytogenetic factors in cervical carcinoma in the Jammu region of $\mathrm{J}$ and $\mathrm{K}$ state. $\mathrm{J}$ Cancer Res Ther 2011; 7(3): 286-91.

24. Vizcaino AP, Moreno V, Bosch FX, Muñoz N, Barros-Dios XM, Parkin DM. International trends in the incidence of cervical cancer: I. Adenocarcinoma and adenosquamous cell carcinomas. Int $\mathrm{J}$ Cancer 1998; 75(4): 536-45. 